\title{
Proposed TPM Implementation Process based on Organisational Readiness for Change
}

\author{
Dr Paisith Susomrith \\ S.S.R. Electric Center Co.Ltd., Thailand \\ Dr Sineenat Rermlawan \\ Faculty of Management Sciences, \\ Rajabhat Rajanagrarindra University, Thailand
}

\begin{abstract}
Total Productive Maintenance (TPM) is the evolution of Preventative Maintenance (PM) and provides greater benefits to an organisation including an increase in productivity and manufacturing efficiency and reduced manufacturing costs. Although the benefits of TPM are well documented numerous barriers have limited the practical application of this theory. Drawing on Lewis' (1951) change model and Weiner (2009) Organisational readiness for change construct this paper proposes an implementation process for TPM that aims to minimise barriers and motivate employees while preventing premature commencement of the implementation phase thereby averting implementation failure. To preserve the change, once TPM has been implemented the change is re-frozen.
\end{abstract}

Keywords: Total Productive Maintenance, TPM, organisational readiness, change model, implementation

\section{INTRODUCTION}

Manufacturing organisations, like all other organisations, must continually find means to remain competitive as the industry is under constant pressure to reduce the cost of goods. The obvious means to achieve this goal is to reduce the manufacturing cost, either the raw material cost or labour costs. This trend leads to the automation age where a proportion of human labour was replaced by machines. This brought its own set of problems such as the need to maintain these machines leading to the inception of maintenance departments who were charged with keeping the machinery running (Jain, Bhatti and Singh, 2014). It was soon realised that machine breakdowns cost the organisation both to fix the machine and lost production time. This leads to the concepts of Preventative Maintenance and finally to Total Productive Maintenance (TPM).

TPM was found to provide an increase in productivity and manufacturing efficiency from $150 \%$ to $200 \%$ while reducing manufacturing costs by $30 \%$. These improvements have been reproduced in countries other than Japan such as India (Katkamwar, Wadatkar, Paropate, 2013). In addition, accidents were reduced, product consistency improved leading to quality improvements. Customer complaints were addressed and customer satisfaction increased. In addition to these direct benefits, TPM also provides a greater feeling of employee ownership of both equipment and within the organisation, an increase in employee confidence, an improvement in employee attitudes to the organisation and between peers as the whole organisations work towards common goals. 
The benefits for TPM were not always achieved and it was soon realised the several barriers existed that prevented the successful implementation of TPM. As the implementation of TPM is essentially an organisation change the Lewin (1951) three step change model may be applied. Together with the Organisational readiness for change construct was used to develop a TPM implementation procedure. This procedure provides a framework to minimise the TPM implementation barriers and boost the TPM drivers leading to improved opportunities for TPM to be successfully implemented.

\section{TOTAL PRODUCTIVE MAINTENANCE (TPM)}

An organisations productivity is directly related to the percentage of time its resources are available to produce a product or service. Maintenance was originally considered a nuisance, required to restore equipment to working order when they broke down. Manufacturing equipment would be used by operators to produce products/services and maintenance personnel would be responsible for keeping the equipment running. It was soon realised that the cost of break downs not only included the cost to repair the equipment but also the loss of time the equipment was unable to produce saleable products/services. Organisations began to understand the need to increase the availability of their resources/equipment through a structured maintenance program which leads to the Preventative Maintenance approach developed in the United States of America (van der Wal and Lynn, 2002). Assisted by automation trends sweeping the industry, organisations become more reliant on manufacturing equipment and the need to keep this equipment operational. By 1960 Nippondenso introduced plant wide preventative maintenance programs, although, to control the ever growing need for more maintenance personnel, Nippondenso management decided to assign routine maintenance to operators thereby allowing maintenance personnel to focus on essential maintenance activities, this became known as Autonomous maintenance.

Relieved of the routine maintenance duties the Nippondenso maintenance personnel could concentrate on improving the reliability of the manufacturing equipment. As these improvements were developed they were also incorporated into new equipment leading to the concept of maintenance prevention. Combining preventative maintenance, maintenance prevention and maintainability improvements lead to Productivity Maintenance with the aim of maximising equipment availability to achieve optimal productivity. Nippondenso continued to improve maintenance processes by enlisting employee participation through quality circles leading to the concept of Total Productivity Maintenance (TPM) whose goal is to increase productivity while simultaneously increasing employee morale and job satisfaction. Nippondenso efforts gain them the distinguished Japanese Institute of Plant Engineers (JIPE) prize for developing and implementing TPM. Nippondenso (Toyota Group) was also the first organisation to obtain TPM certification.

TPM share many similarities with Total Quality Management (TQM) such that they are often used interchangeably. For example, both approaches are based on an organisational commitment driven by management. But these two approaches are very different, where TPM focuses on the equipment used to manufacture products; TQM is concerned with the quality of the manufactured products. It can be argued that TPM leads an improvement in the condition of manufacturing equipment which translates to better quality of products but this in only a subset of TQM. The aim of TQM is to increase the quality of manufactured products or services by making all sections of the organisation aware of quality concerns. The basis of TQM includes the product, the process (manufacturing), the organisation, leadership and commitment. It is not difficult to see that TPM is an integral part of TQM. 
The benefits of TPM including the minimisation of unscheduled and emergency maintenance established its place as an important component of the business (Dwyer, 1999). Maintenance was no longer considered a non-profit activity but an essential part of the manufacturing process. The Vice-Chairman of Japanese Institute of Plant Engineers (JIPE), Siiechi Nakajima (also known as the father of TPM) states "TPM is a system of maintenance covering the entire life of the equipment in every division including planning, manufacturing, and maintenance". The Japanese Institute of Plant Engineers (JIPE) defined the TPM initiative using an eight pillar implementation plan with the goal of maximising equipment effectiveness by developing a preventative maintenance plan for the lifespan of the equipment through the involvement of the entire organisation by the motivation of management and small group activity. As shown in Figure 1, the TPM eight pillars include: (1) autonomous maintenance; (2) focused maintenance; (3) planned maintenance; (4) quality maintenance; (5) education and training; (6) office TPM; (7) development management; and (8) safety, health and environment (Idris, Ibrahim, Sari, 2017; Ireland and Dale, 2001; Rodrigues and Hatakeyama, 2006; Shamsuddin, Hassan and Taha, 2005).

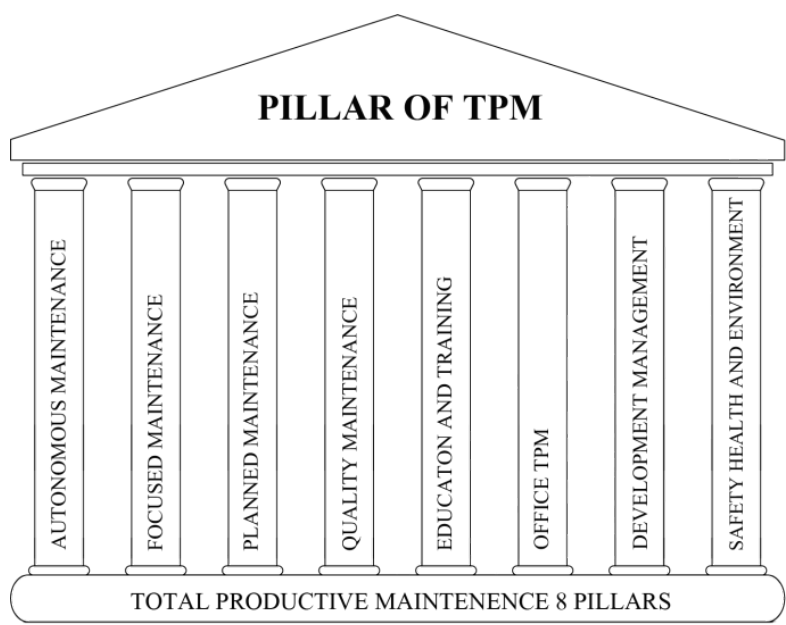

Figure 1: The Eight Pillars of Total Productive Maintenance (TPM)

TPM requires complete support within an organisation to succeed from employee cooperation to management support and leadership (Idris, Ibrahim, and Sari, 2017). Without these elements it is unlikely TPM will be established. Researchers have identified three major barriers that jeopardise the implementation of TPM: Cultural resistance, Lack of management support and commitment, and lack of training (Attri, Grover, Dev and Kumar, 2013).

Cultural resistance to change hinders the cooperation of employees due to fears of the unknown and preference to retain the status quo. Without overall employee participation the TPM initiatives are likely to fail. The responsibility falls on management to motivate and communicate the benefits of TPM for both the organisation and the employees. With this change in culture the TPM will fail (Lawrence, 1999). Management must also understand that cultural change may only occur over a significant period of time, three to five years (Bamber, Sharp and Hides, 1999). Cultural change can only occur through management's commitment to TPM and training of employees.

TPM implementation starts with management commitment and motivation to communicate the benefits, provide time, training and a structured program for employees to participate and fund the initial maintenance effort to bring equipment up to a particular condition (Patterson, Fredendall, Kennedy and McGee, 1996; Park and Han 2001). A common barrier to TPM implementation that reoccurs in literature is the lack of management support and commitment (Chan, Lau, Ip, Chan and Kong, 2005; Co, Patuwo, and Hu, 1998; Rodrigues and Hatakeyama, 
2006; Tsang and Chan, 2000) such as through a misunderstanding of TPM, for example, management believing that TPM will allow maintenance activities to be transferred to equipment operators leading to a reduction of maintenance personnel (Bamber, Sharp and Hides, 1999). This misunderstanding by management may lead to employees fearing that managements aim is to reduce staff, increase responsibilities, production and workload (Ahuja and Khamba, 2008a).

Lack of training has been identified as a main barrier to successful TPM implementation (Adam et al., 1997; Chan, Lau, Ip, Chan and Kong, 2005; Co, Patuwo, and Hu, 1998; Rodrigues and Hatakeyama, 2006) where training includes both technical (equipment maintenance) and process (TPM). Davis (1997) found that lack of technical equipment training resulted in a reduction of equipment effectiveness which subsequently leads to TPM failure in UK manufacturing organisations. In terms of process, training is considered vital to change an organisations mindset from the traditional maintenance approach to TPM (Ahuja and Khamba, 2008a; Bamber, Sharp and Hides, 1999; Becker, 1993). Process training should commence as early as possible, during the initial phases of TPM implementation (Blanchard, 1997) to avert reluctance of employees to accept change. The transfer of routine maintenance activities from maintenance personnel to production staff is usually met with resistance as maintenance personnel do not believe production staff have the skills or knowledge to undertake these tasks. Similarly, production staff are reluctant to take on the routine maintenance activities as this will affect their production performance (Cooke, 2000). Lawrence (1999) found maintenance personnel were concerned that production staff would fail to perform their assigned maintenance tasks appropriately resulting in equipment failure which they would then be expected to fix. Similar conflicts between departments have been identified by Ahuja and Khamba (2008a, b) in Indian manufacturing organisations.

\section{ORGANISATIONAL READINESS FOR CHANGE}

To successful implement change such as transition from PM to TPM within an organisation is laden with challenges. Organisation must prepare to meet these challenges otherwise all efforts to implement the change will be in vain. It has been found that an organisation who fails to prepare for a change account for 50 percent of all failed organisational change efforts. Preparation for change pertains to the first stage of Lewin (1951) three steps of change model. The Lewin (1951) change model includes the stages; (1) unfreeze, (2) moving, and (3) refreezing. Unfreezing refers to the process of identifying and breaking down the forces preventing change while strengthening the driving forces. The moving stage encompasses the implementation of the change. The refreezing stage sustains the change through the process of reinforcement. Based on the Lewin's change model Bozak (2003) proposed a framework for the change of a nursing information system from a paper documentation system to an electronic system. Bozak (2003) developed strategies to reduce barriers for the change and boost the change drivers. Strategies to unfreeze an organisation include generating dissatisfaction with the current status, building desire for the future state, highlighting the differences and demonstrating confidence the future state can be attained.

Organisational readiness for change was defined by Weiner (2009) and encompassed the concepts of 'change commitment' and 'change efficacy'. Change commitment refers to the belief that a change is needed which will address current organisational issues, the change will provide benefits or value, the change better matches the organisation's members core values, or the change is supported by peers, leaders or managers. The actual motivation for change may differ between organisation members. The reason why organisational members agree with the change is not as important as their collective value and commit to the change. 
Change efficacy describes the belief the organisation possess the resources to undertake the task. Three determinates that define change efficacy include task demands, resource availability and situational factors. Organisational member assess the proposed change by considering the effort required to implement the change, broken down into tasks. The available resource to implement the change is considered in relation to the considered tasks. Situational factors are also considered such as the time available to undertake the change. When organisational members perceive favourable change efficacy they gain confidence that the change can occur leading to greater desire to initiate the change, better cooperative behaviour and higher persistence to overcome obstacles. Weiner's (2009) model for Organisational readiness for change is shown in Figure 1.

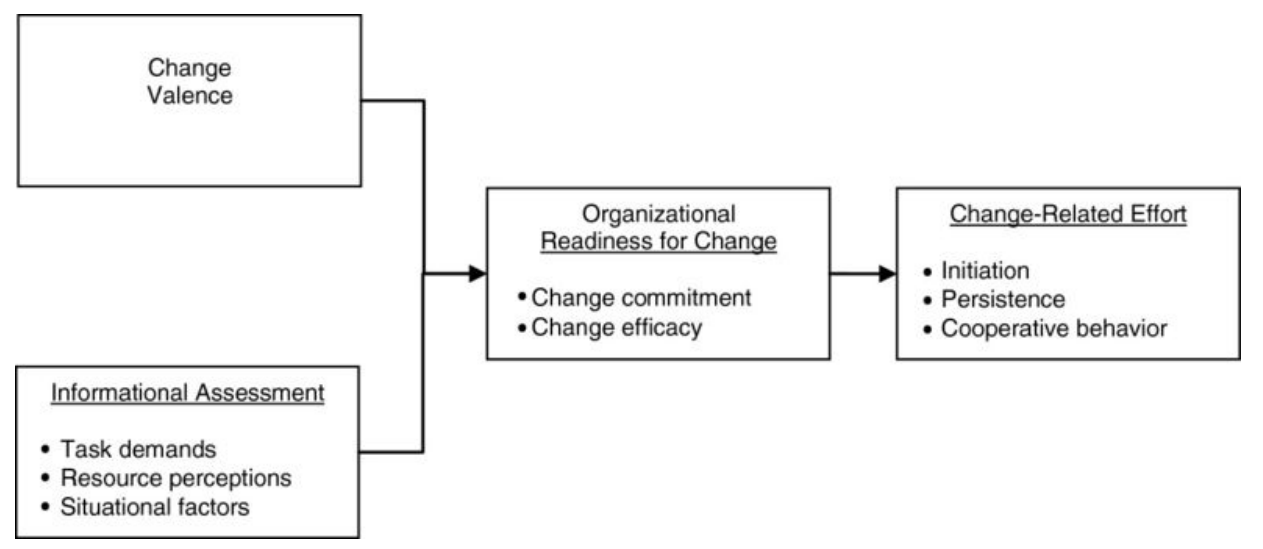

Figure 2: Determinants and Outcomes of Organizational Readiness for Change.

*Adapted from Weiner, B.J., 2009, A theory of organizational readiness for change. $p$. 67.

Based on the three concepts of TPM, organisational readiness for change and Lewin (1951) three steps of change model the proposed TPM implementation process was developed as shown in Figure 2. This process covers the Lewin (1951) three steps of change. The unfreezing step entails the minimisation of the TPM implementation barriers, employing organisational readiness for change to prevent premature implementation attempts. Once the organisation is sufficiently ready then implementation of TPM can commence thereby improving the chances of the implementation succeeding. The freezing step includes the reinforcement of TPM, measuring business performance and job satisfaction to determine when TPM is entrenched within the organisation.

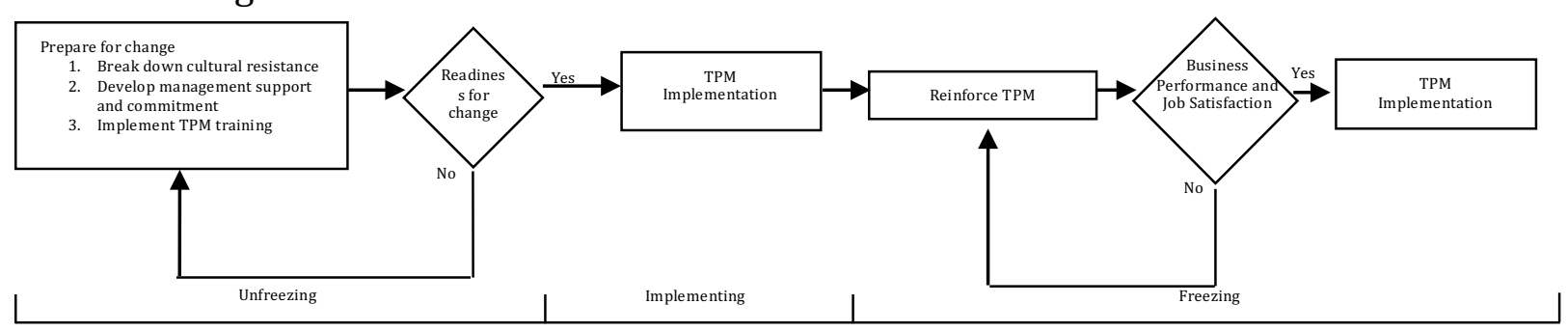

Figure 3: The Proposed Total Productive Maintenance (TPM) Implementation Process

\section{CONCLUSION}

TPM has been demonstrated to provide particular businesses including but to limited to mines, manufacturing plants, processing plants, construction, building maintenance and logistics with a competitive edge. The goal of TPM is to maximise productivity while simultaneously involving employees and improving job satisfaction. Even with the benefits TPM, the implementation of this approach is fraught with challenges including the lack of support and commitment by the organisation, cultural resistance from the employees and lack of training. 
To improve the chance of successful introduction and implementation it is vital to minimise these barriers. It is proposed that the concept of organisational readiness for change and Lewin (1951) three steps of change model may be used to improve the chances for an organisation to successfully implement TPM.

Using the concepts of change commitment and change efficacy, organisational readiness for change may provide managers with the tools and guidance to minimise the barriers to TPM while generating the motivation and cooperation of the employees. Readiness for change provides the gateway to commence the TPM implementation while reinforcement techniques ensure the TPM process has the best opportunity to be established within the organisation.

Future research in this field is encouraged to seek answers to the following questions; does the concept of organisational readiness for change directly affect the successful implementation of TPM? Is the organisational readiness for change and TPM relationship consistent across different organisation types? And is organisational readiness for change sufficient for successful TPM implementation? Answers to these questions would assist managers to gauge an organisation's readiness to implement TPM. Organisations with insufficient readiness could be further prepared thereby adverting a potential TPM implementation failure.

\section{References}

Adam, E.E., Corbett, L.M., Flores, B.E., Harrison, N.J., Lee, T.S., Rho, B.H., Ribera, J., Samson, D. and Westbrook, R. (1997). "An international study of quality improvement approach and firm performance", International Journal of Operational Product Management, Vol. 17 No. 9, pp. 842-873.

Ahuja, I.P.S. and Khamba, J.S. (2008a). "Assessment of contributions of successful TPM initiatives towards competitive manufacturing", Journal of Quality in Maintenance Engineering, Vol. 14 No. 4, pp. 356-374.

Ahuja, I.P.S. and Khamba, J.S. (2008b), “Total productive maintenance: literature review and directions”, International Journal of Quality and Reliability Management, Vol. 25 No. 7, pp. 709-756.

Attri, R., Grover, S., Dev, N. and Kumar, D. (2013). “Analysis of barriers of Total Productive Maintenance (TPM)”, International Journal of System Assurance in Engineering Management, Vol. 4 No. 4, pp. 365-377.

Bamber, C.J., Sharp, J.M. and Hides, M.T. (1999). "Factors affecting successful implementation of total productive maintenance: A UK manufacturing case study perspective”, Journal of Quality in Maintenance Engineering, Vol. 5 No. 3, pp. 162-181.

Becker, S.W. (1993). “TQM does work: ten reasons why misguided efforts fail”, Management Review, Vol. 82 No. 5 , pp. 30-34.

Blanchard, B.S. (1997). "An enhanced approach for implementing total productive maintenance in the manufacturing environment”, Journal of Quality in Maintenance Engineering, Vol. 3 No. 2, pp. 69-80.

Bozak, M.G. (2003). "Using Lewin's force field analysis in implementing a nursing information system”, CIN: Computers, Informatics, Nursing, Vol. 21 No. 2, pp. 80-85.

Chan, F.T.S., Lau, H.C.W., Ip, R.W.L., Chan, H.K. and Kong, S. (2005). “Implementation of total productive maintenance: A case study”, International Journal of Production Economics, Vol. 95, pp. 71-94.

Co, H.C., Patuwo, B.E. and Hu, M.Y. (1998). "The human factor in advanced manufacturing technology adoption: An empirical analysis", International Journal of Operational and Production Management, Vol. 18 No. 1, pp. 87-106.

Cooke, F.L. (2000). “Implementing TPM in plant maintenance: some organizational barriers”, International Journal of Quality Reliability Management, Vol. 17 No. 9, pp. 1003-1016.

Davis, R. (1997). "Making TPM a part of factory life”, Works Management, Vol. 49, pp. 16-17.

Dwyer, J. (1999), “More than a maintenance technique”, Works Management, Vol. 52 No. 9, pp. 15-16.

Idris, I., Ibrahim, I. and Sari, R.A. (2015). Implementation of eight pillars the total productive maintenance at Water Supple Company, Journal of Engineering Science, Vol. 1 No. 2.

Ireland, F. and Dale, B.G. (2001). "A study of total productive maintenance implementation", Journal of Quality Maintenance in Engineering, Vol. 7 No. 3, pp. 183-192. 
Jain, A., Bhatti, R. and Singh, H. (2014). "Total productive maintenance (TPM): a proposed model for Indian SMEs", International Journal of Mechanical and Production Engineering Research and Development, Vol. 4 No. 1, pp. 1-22.

Jostes, R.S. and Helms, M.M. (1994). “Total productive maintenance and its link to total quality management”, Work Study, Vol. 43 No. 7, pp. 18-20.

Katkamwar, S.G., Wadatkar, S.K. and Paropate, R.V. (2013). "Study of total productive maintenance \& its implementing approach in spinning industries", International Journal of Engineering Trends and Technology, Vol. 4 No. 5, pp. 1750-1754.

Lawrence, J.J. (1999). "Use mathematical modelling to give your TPM implementation effort an extra boost", Journal of Quality in Maintenance Engineering, Vol. 5 No. 1, pp. 62-69.

Lewin, K. (1951). Field theory in social science: Selected theoretical papers. D. Cartwright, New York.

Park, K.S. and Han, S.W. (2001). "Total productive maintenance: Impact on competitiveness and framework for successful implementation", Human Factors and Ergonomics in Manufacturing, Vol. 11 No. 4, pp. 321-338.

Patterson, J.W., Fredendall, L.D., Kennedy, W.J. and McGee, A. (1996). "Adapting total productive maintenance to Asten Inc., Product Inventory Management Journal, Vol. 37 No. 4, pp.32-36.

Rodrigues, M. and Hatakeyama, K. (2006). "Analysis of the fall of TPM in companies", Journal of Materials Processing Technology, Vol. 179 No. 1-3, pp. 276-279.

Shamsuddin, A., Hassan, M.H. and Taha, Z.(2005). "TPM can go beyond maintenance excerpt from a case implementation", Journal of Quality in Maintenance Engineering, Vol. 11 No. 1, pp. 19-42.

Tsang, A.H.C. and Chan, P.K. (2000). "TPM Implementation in China: a case study", International Journal of Quality Reliability Management, Vol. 17 No. 2, pp. 144-157.

van der Wal, R.W.E. and Lynn, D. (2002). "Total Productive Maintenance in a South African pulp and paper company: a case study", The TQM Magazine, Vol. 14 No. 6, pp. 359-366.

Weiner, B.J. (2009). A theory of organizational readiness for change. Implementation Science, Vol. 4 No. 1, p. 67. 